Journal of Current and Advance Medical Research

January 2020, Vol. 7, No. 1, pp. 17-23

http://www.banglajol.info/index.php/JCAMR

ISSN (Print) 2313-447X

ISSN (Online) 2413-323X

NLM Catalog ID 101673828

DOI: https://doi.org/10.3329/jcamr.v7i1.46425

ORIGINAL ARTICLE

\title{
OPEN@ACCESS
}

\section{Sonographic Study of Female Pelvic Organs in Breast Cancer Patients Taking Tamoxifen: Clinical Correlation}

\author{
Rafia Parveen ${ }^{1}$, Shaikh Shofiur Rahman ${ }^{2}$, Taposhi Sarker ${ }^{3}$, Syed Muhammad Baqui Billah ${ }^{4}$, Zakir \\ Hossain Habib ${ }^{5}$
}

\begin{abstract}
${ }^{1}$ Associate Professor, Department of Radiology \& Imaging, Delta Medical College \& Hospital, Dhaka, Bangladesh; ${ }^{2}$ Professor \& Head, Department of Radiology \& Imaging, Delta Medical College \& Hospital, Dhaka, Bangladesh; ${ }^{3}$ Assistant Professor, Department of Radiology \& Imaging, Delta Medical College, Dhaka, Bangladesh; ${ }^{4}$ Assistant Professor, Department of Epidemiology, Sulaiman Al Rajhi University, Saudi Arabia; ${ }^{5}$ Associate Professor, Department of Microbiology, Institute of Epidemiology, Disease Control \& Research (IEDCR) Dhaka, Bangladesh
\end{abstract}

[Received on: 2 October 2019; Accepted on: 1 December 2019; Published on: 1 January 2020]

\section{Abstract}

Background: As most of breast cancer patients are treated with Tamoxifen, different effects of this drug in patients should be evaluated since no such study is carried out in Bangladesh till date. Objective: The purpose of the present study was to evaluate sonographic changes of female genital organs in breast cancer patients treated with Tamoxifen and to correlate these changes with duration of Tamoxifen treatment and gynecological symptoms. Methodology: This randomized double-blind clinical trial was carried out in Delta Medical College Hospital, Dhaka, Bangladesh from May 2017 to April 2018 for a period of one (1) year. The participants were breast cancer patients which were divided into three groups named as group I patients. The patients of these group were on Tamoxifen therapy. The patients of group II were without Tamoxifen therapy. The patients of group III had completed Tamoxifen therapy. All participants underwent ultrasonography. Results: Patients receiving Tamoxifen therapy had significantly more thickened endometrium compared to other groups (26.6\% in group I, $5 \%$ in group II and3\% in group III). Similarly, abnormal sonographic findings and mean uterine volume were higher in group I compared to other two groups. Endometrial thickness and uterine volume showed significant positive correlation with duration of Tamoxifen therapy $(\mathrm{p}<0.0001)$. The endometrial thickness and uterine volume greatly increased after two years of Tamoxifen therapy while it was reverse in group III. Gynecological symptoms had no significant relations with sonographic abnormalities and thickened endometrium. Conclusion: Tamoxifen therapy is associated with increased endometrial thickness, uterine volume and abnormal sonographic findings, compared to patients without Tamoxifen or completing Tamoxifen therapy. [Journal of Current and Advance Medical Research, January 2020;7(1):17-23]

Keywords: Breast cancer; Tamoxifen; sonography; endometrium

Correspondence: Dr. Rafia Parveen, Associate Professor, Department of Radiology \& Imaging, Delta Medical College \& Hospital, Dhaka, Bangladesh; Email: prafia08@yahoo.com; Cell no.: +8801716605274

Cite this article as: Parveen R, Rahman SS, Sarker T, Billah SMB, Habib ZH. Sonographic Study of Female Pelvic Organs in Breast Cancer Patients Taking Tamoxifen: Clinical Correlation. J Curr Adv Med Res 2020;7(1):17-23

Funding: This research did not receive any grant from any funding agency in the public, commercial or not-for-profit sector.

Conflict of Interest: The authors declare that there is no conflict of interest that could be perceived as prejudicing the impartiality of the research reported.

Contributions to authors: Parveen R, Rahman SS, Sarker T involved in protocol preparation, data collection; statistical analysis Parveen R. Billah SMB, Habib ZH had involved in manuscript writing \& revision of the manuscript.

Copyright: (02020. Parveen et al. Published by Journal of Current and Advance Medical Research. This article is published under the Creative Commons CC BY-NC License (https://creativecommons.org/licenses/by-nc/4.0/). This license permits use, distribution and reproduction in any medium, provided the original work is properly cited, and is not used for commercial purposes. 


\section{Introduction}

Breast cancer is the most common cancer in women with worldwide high incidence including Bangladesh. According to global cancer statistics, more than 2 million new breast cancer cases were diagnosed ${ }^{1}$. Tamoxifen is a selective non-steroidal estrogen receptor modulator that is commonly used as adjuvant therapy in the treatment of primary and metastatic breast cancer and prevention of breast cancer in high-risk women ${ }^{2-4}$.

The drug shows anti-oestrogenic activity on breast and oestrogenic effects on uterus, ovaries, bone, liver and cardiovascular system ${ }^{2,5}$. Tamoxifen may cause endometrial thickening ${ }^{6,7,8}$, endometrial hyperplasia ${ }^{6,7,9,10}$, increased uterine volume ${ }^{11,12,13}$, endometrial polyps ${ }^{6,10}$, increase in the size of uterine leiomyomata ${ }^{7}$, endometriosis ${ }^{14}$, ovarian cysts $^{6,14}$. The most serious adverse effect of Tamoxifen is risks of developing endometrial cancer $^{5,10,15,17,18}$ and uterine sarcoma ${ }^{7,10,17}$.

Reports suggest that the risk, incidence and severity of endometrial cancer increases with dose and duration of Tamoxifentherapy ${ }^{7,16,10,17}$. Ashraf et al $^{19}$ studied adverse effects of Tamoxifen on 3,000 Indian women. Hot flashes, fatty infiltration of liver, mild vaginal dryness, vaginal discharge and vaginal bleeding were seen in some patients. A good proportion of asymptomatic patients had a thickened endometrium.

Vosse et $\mathrm{al}^{20}$ conducted a study on 3 groups of postmenopausal women. Group I comprised of breast cancer patients on Tamoxifen, group II had breast cancer patients without Tamoxifen intake and group III had women without breast cancer or Tamoxifen therapy. Initial mean endometrial thicknesses were $8.2 \mathrm{~mm}$ in group I, $4.4 \mathrm{~mm}$ in group II and $3.4 \mathrm{~mm}$ in group III. Endometrial lesions were most common in Tamoxifen group. A significant association was observed between endometrial pathologies and both cumulated dose and total duration of Tamoxifen therapy. Polyps were the most frequent pathology. 5 cancers were detected in group I, all of whom had taken Tamoxifen for more than 3 years.

American College of Obstetricians and Gynecologists recommend that women taking Tamoxifen should be informed about the risks of Tamoxifen use including endometrial cancer. Any abnormal vaginal bleeding, bloody vaginal discharge, staining or spotting in these patients should be investigated. Periodic monitoring should be done, when indicated ${ }^{2}$. To the best of our knowledge, no study has been carried out in Bangladesh so far to evaluate the effects of Tamoxifen on female genital organs. The purpose of this study is to evaluate the effects of Tamoxifen on female genital organs in breast cancer patients, as evident by clinical and sonographic methods.

\section{Methodology}

This was a randomized, double-blind clinical trial carried out in Delta Medical College Hospital, Dhaka, Bangladesh from May 2017 to April 2018 for a period of one (1) year. The study was approved by Ethical Committee of Delta Medical College Hospital. Breast cancer patients with or without undergoing Tamoxifen therapy or completed this treatment or, women who had taken hormone replacement therapy or oral contraceptives within six months and who had undergone hysterectomy were included as study population. The study included total 320 breast cancer patients who were advised pelvic sonography during their follow up visits. Among them, 154 were menstruating women and 166 were postmenopausal women. The participants were divided into 3 groups: group I $(\mathrm{n}=150$, patients taking Tamoxifen tablet $20 \mathrm{mg}$ per day for at least six months), group II $(n=140$, patients not taking Tamoxifen tablet) and group III $(\mathrm{n}=30$, patients who have already completed Tamoxifen therapy). Group I patients received Tamoxifen tablet for a mean period of $29.1 \pm 6.5$ months (ranging 6 months to 72 months). After taking informed written consent, all patients were asked about Tamoxifen therapy and any gynecological symptoms. Each patient had undergone transabdominal and transvaginal sonography (TVS) using Akola 500 system and Philips Affinity 50G machines. The endometrial thickness was measured on midline sagittal scan from anterior to posterior endometrium. Care was taken not to include hypoechoic myometrium or intrauterine fluid in this measurement. Endometrial cysts were defined as more than one hypoechoic area greater than $1 \mathrm{~mm}$ in maximum diameter. Endometrial polyp was defined as protrusion into endometrium greater than $5 \mathrm{~mm}$ in maximum diameter. Menopause was defined as cessation of menstruation for at least 1 year. For postmenopausal and amenorrheic premenopausal women, endometrial thickening was defined as endometrial thickness $>8 \mathrm{~mm}$ and $>12$ $\mathrm{mm}$ for women with regular menstruation. Volume of uterus was measured in all patients using the following formula: Volume $=0.5233 \mathrm{X}$ length $\mathrm{X}$ width X AP diameter ${ }^{21}$. Endometrial thickness and uterine volume was assessed with duration of 
Tamoxifen treatment and gynecological symptoms. Statistical analysis was performed using the SPSS software version 23.0. The qualitative variables were assessed with the Chi-square test, while the continuous variables were assessed with t-test or ANOVA, as applicable. The distribution of duration was divided into two groups, one is $\leq 2$ years and $>2$ years.

We plotted error bars to assess the relationship of treatment duration or duration after completion of treatment with endometrial thickness and uterine volume. A p value of $<0.05$ was considered as statistically significant.

\section{Result}

Age distribution of the 3 groups is shown in Table 1. The mean age of participants was $47.37 \pm 9.83$ years with the range of 23 to 78 years. No association was seen between the three patient groups and the age group, though the group III patients were a bit older compared to other two $(\mathrm{p}=0.03)$.

Table 1: Age Distribution of the Patients in 3 Groups

\begin{tabular}{|c|c|c|c|c|c|}
\hline Age Group & Group I & Group II & Group III & Total & P value \\
\hline 20 to 30 Years & $5(3.3 \%)$ & $6(4.3 \%)$ & $0(0.0 \%)$ & $11(3.4 \%)$ & \multirow{7}{*}{$0.45^{*}$} \\
\hline 31 to 40 Years & $38(25.3 \%)$ & $27(19.3 \%)$ & $5(16.7 \%)$ & $70(21.8 \%)$ & \\
\hline 41 to 50 Years & $66(44.0 \%)$ & $53(37.9 \%)$ & $12(40.0 \%)$ & $131(40.9 \%)$ & \\
\hline 51 to 60 Years & $32(21.3 \%)$ & $37(26.4 \%)$ & $8(26.7 \%)$ & $77(24 \%)$ & \\
\hline 61 to 70 Years & $9(6.0 \%)$ & $16(11.4 \%)$ & $5(16.7 \%)$ & $30(9.3 \%)$ & \\
\hline 71 to 80 Years & $0(0.0 \%)$ & $1(0.7 \%)$ & $0(0.0 \%)$ & $1(0.3 \%)$ & \\
\hline Total & 150 & 140 & 30 & 320 & \\
\hline Mean \pm SD & $46.10 \pm 9.21$ & $47.96 \pm 10.49$ & $50.93 \pm 8.74$ & $47.37 \pm 9.83$ & $0.03^{* *}$ \\
\hline
\end{tabular}

*Chi-square test was performed to see the level of significance; **Student $t$ test was done to see the level of significance

The distribution of thickened endometrium, sonographic abnormalities and mean uterine volume of three groups of patient were recorded. Tamoxifen group (Group I) showed significant number of thickened endometrium, sonographic abnormalities and larger mean uterine volume compared to other two groups. Among total 320 patients, 10 patients $(3.1 \%)$ had gynecological symptoms. Gynecological symptoms like postmenopausal bleeding, irregular period, heavy period or per-vaginal discharge were found in $7(4.7 \%)$ patients of Tamoxifen group, 2(1.4\%) patients of control group and 1(3.3\%) case of completed group. No significant correlation was found between gynecological symptoms in these three groups. Even there was no relation between gynecological symptoms and sonographic abnormalities.

Table 2: Thickened Endometrium, Ultrasonography and Mean Uterine Volumes in 3 Groups

\begin{tabular}{|l|c|c|c|c|c|}
\hline Findings & Group I & Group II & Group III & Total & P Value \\
\hline Thick endometrium & $55(36.7 \%)$ & $16(11.4 \%)$ & $3(10.0 \%)$ & $74(23.1 \%)$ & 0.001 \\
\hline Sonographic abnormality & $35(23.3 \%)$ & $10(7.1 \%)$ & $1(3.3 \%)$ & $46(14.3 \%)$ & 0.001 \\
\hline Gynecological symptoms & $7(4.7 \%)$ & $2(1.4 \%)$ & $1(3.3 \%)$ & $10(0.31 \%)$ & 0.17 \\
\hline Mean Uterine Volume(cc) & $79.3 \pm 36.58$ & $55.8 \pm 23.19$ & $57.5 \pm 26.84$ & & 0.001 \\
\hline
\end{tabular}

Correlation of duration of Tamoxifen therapy with endometrial thickness and mean uterine volume were assessed in Tamoxifen group (Group-I) which showed statistically significant $(\mathrm{p}<0.0001$ and 0.001 respectively) positive correlation.

On the other hand, there was a negative correlation of mean endometrium thickness with duration after therapy completion, though the relation was not significant.

In the same manner, the uterine volume showed no correlation with the duration after therapy completion in group III (Table 3). 
Table 3: Correlation of Duration of Tamoxifen Therapy (Group I) and Duration of Therapy Completion (Group III) With Endometrial Thickness and Uterine Volume

\begin{tabular}{|l|c|c|c|c|}
\hline \multirow{2}{*}{$\begin{array}{l}\text { Dependent } \\
\text { variable }\end{array}$} & \multicolumn{2}{|c|}{ Group I } & \multicolumn{2}{c|}{ Group III } \\
\cline { 2 - 5 } & $\begin{array}{c}\text { r } \\
\text { value }\end{array}$ & P value & $\begin{array}{c}\text { r } \\
\text { value }\end{array}$ & $\begin{array}{c}\text { P } \\
\text { value }\end{array}$ \\
\hline $\begin{array}{l}\text { Endometrial } \\
\text { thickness }\end{array}$ & 0.43 & $<0.001$ & -0.23 & 0.23 \\
\hline $\begin{array}{l}\text { Uterine } \\
\text { volume }\end{array}$ & 0.27 & 0.001 & 0.001 & 0.99 \\
\hline
\end{tabular}

Unique finding from the study: While we observed the change of endometrial thickness and uterine volume with group I over time, we checked the frequency and found that there was an interesting difference of changes of endometrial thickness and uterine volume before and after 2 years. We assessed these changes and found that after 2 years there was significant increase of endometrial thickness (before $7.12 \pm 2.29 \mathrm{~mm}$, after $10.11 \pm 4.44 \mathrm{~mm} ; \mathrm{p}<0.001)$ and uterine volume (before $70.15 \pm 28.70 \mathrm{ml}$, after $86.55 \pm 40.46 \mathrm{ml}$; $\mathrm{p}=0.004$ ). While we checked this for those who completed Tamoxifen therapy (group III) we found that there was no difference of endometrial thickness nor uterine volume, indicating that these parameters came back to normal after cessation of therapy (Figure I to IV).

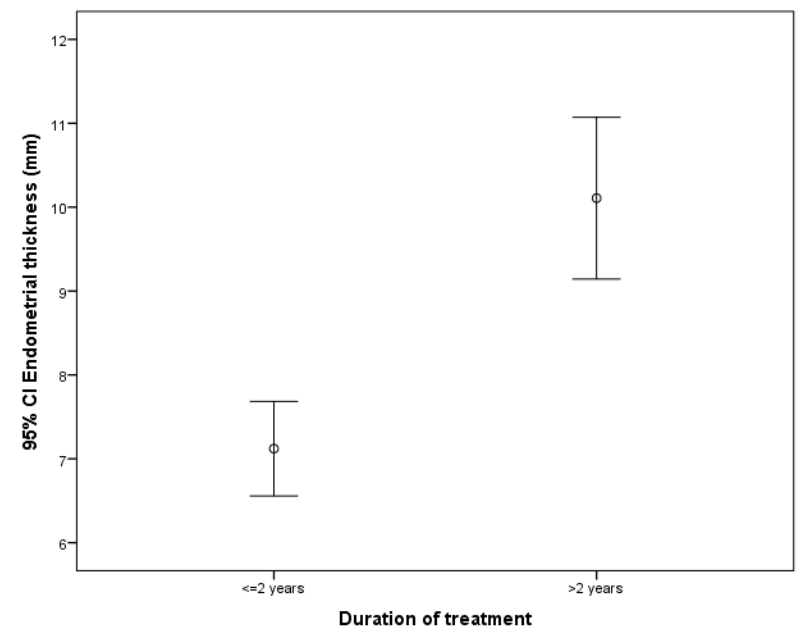

Figure I: Duration of Treatment with Endometrial Thickness (Group I)

Table 4 shows distribution of sonographic abnormalities in 3 groups of patients. Most frequent abnormalities were inhomogeneous endometrium, endometrial cysts and endometrial polyps.

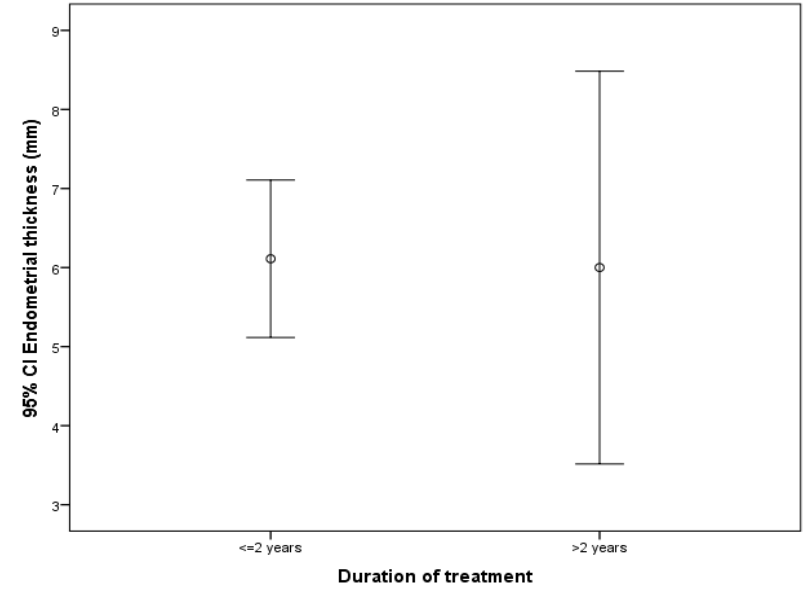

Figure II: Duration after completion of treatment with Endometrial Thickness (Group III)

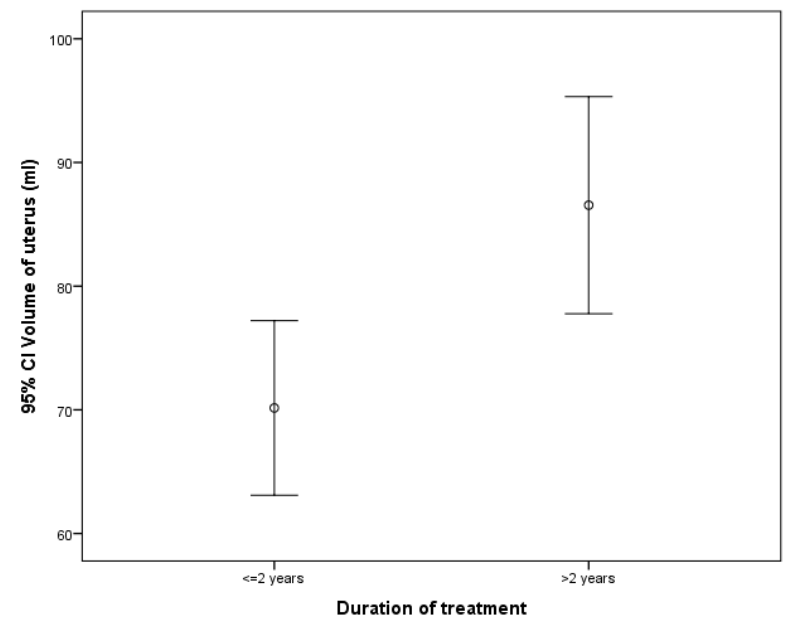

Figure III: Duration of Treatment with Uterine volume (Group I)

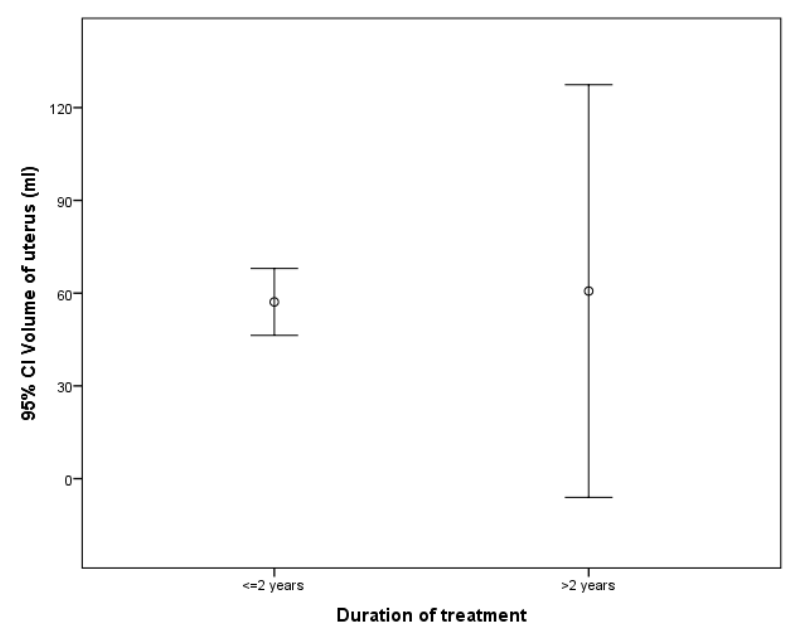

Figure IV: Duration after completion of treatment with Uterine volume (Group III) 
Table 4: Abnormal Sonographic Findings in 3 groups

\begin{tabular}{|l|l|c|}
\hline Group & Sonographic findings & Number \\
\hline Group-I & $\begin{array}{l}\text { Inhomogeneous } \\
\text { Endometrium }\end{array}$ & 7 \\
\cline { 2 - 3 } & Endometrial cyst & 7 \\
\cline { 2 - 3 } & Endometrial polyp & 6 \\
\cline { 2 - 3 } & Adnexal cyst & 5 \\
\cline { 2 - 3 } & Endometrial collection & 5 \\
\cline { 2 - 3 } & $\begin{array}{l}\text { Endometrial cyst with } \\
\text { adnexal cyst }\end{array}$ & 3 \\
\cline { 2 - 3 } & Endometrial mass & 2 \\
\cline { 2 - 3 } & $\begin{array}{l}\text { Pelvic inflammatory } \\
\text { disease }\end{array}$ & 1 \\
\cline { 2 - 3 } & Bilateral adnexal masses & 1 \\
\cline { 2 - 3 } & $\begin{array}{l}\text { Endometrial } \\
\text { mass+adnexal cyst }\end{array}$ & 1 \\
\hline Group-II & Endometrial cyst & 1 \\
\cline { 2 - 3 } & Adnexal cyst & 3 \\
\cline { 2 - 3 } & $\begin{array}{l}\text { Pelvic inflammatory } \\
\text { disease }\end{array}$ & 2 \\
\cline { 2 - 3 } & Endometrial collection & 1 \\
\cline { 2 - 3 } & Endometrial polyp & 1 \\
\hline Group-III & $\begin{array}{l}\text { Inhomogeneous } \\
\text { Endometrium }\end{array}$ & 1 \\
\hline
\end{tabular}

\section{Discussion}

Many studies have shown Tamoxifen therapy in breast cancer patients is related with increased number of endometrial abnormalities. Kim et $\mathrm{al}^{22}$ found pathological changes in significant number of breast cancer patients treated with Tamoxifen namely endometrial polyps, proliferative endometrium, submucosal myoma, simple hyperplasia, atrophic endometrium and ovarian cysts. Teixeira et $\mathrm{al}^{16}$ found $5.8 \%$ atrophy, $29.4 \%$ polyps, $11.7 \%$ hyperplasia and $5.8 \%$ endometrial carcinoma in Tamoxifen treated patients. In present study, ultrasonographic abnormalities were found in significant number of patients on Tamoxifen therapy.

In several reports of Tamoxifen use, the most frequent Tamoxifen-induced endometrial abnormalities were polyps $s^{5,10,18,20,22,23}$. In current study, the most frequent pathologies are inhomogeneous endometrium, endometrial cysts and endometrial polyps. Kalampokas et $\mathrm{al}^{23}$ and Ashraf et $\mathrm{al}^{19}$ found thickened endometrium in $40 \%$ and $36.6 \%$ Tamoxifen-treated patients, respectively. The present study shows thick endometrium in $26.6 \%$ patients of Tamoxifen group, $5 \%$ in control group and $3.3 \%$ in Tamoxifen completed group.
In some studies, significantly larger uterus, thicker endometrium, polyps, endometrial fluid collection and heterogeneous endometrial echotexture were found in Tamoxifen-treated women $^{22,23,24}$. Studies by Gupta et $\mathrm{al}^{8}$, Fishman et $\mathrm{al}^{24}$ and Hummeida et $\mathrm{al}^{25}$ showed thickened endometrium in significant number of Tamoxifentreated patients, their studies showed significant positive correlations between endometrial thickness and duration of Tamoxifen therapy.

We also found correlation of endometrial thickness and uterine volume with duration of Tamoxifen therapy. In study by Fishman et $\mathrm{al}^{24}$, endometrial thickness increases gradually with duration of Tamoxifen therapy and decreases slowly after completion of the therapy. Menada et $\mathrm{al}^{26}$ found a statistically significant reduction in endometrial thickness at 6 months after discontinuation of Tamoxifen therapy. We found a negative though non-significant correlation of endometrial thickness with duration after completion of therapy in Tamoxifen-treated patients. Study by Hann et al ${ }^{27}$ on 91 post-menopausal women has shown significant increased endometrial thickness in patients on Tamoxifen for 5 years or more $(14 \mathrm{~mm}$ compared to $5 \mathrm{~mm}$ in patients on Tamoxifen for less than 5 years). Our study revealed a unique finding of endometrial thickness increase of $10 \mathrm{~mm}$ after two years compared to $6 \mathrm{~mm}$ before. Including this, our study also found similar fashion of increase in uterine volume after two years in Tamoxifen group (Figure 3). These findings suggest that we need to investigate deep into the relation of Tamoxifen therapy duration and endometrial thickness or uterine volume.

Risk of endometrial cancer increases with duration of Tamoxifen therapy. In a study by Hann et $\mathrm{al}^{27}$ on 91 breast cancer patients, 2 endometrial cancers were found in women who were treated with Tamoxifen for 6 years. Donne et $\mathrm{al}^{28}$ found higher incidence of endometrial cancer in patients exposed to Tamoxifen for more than four years. In present study, endometrial masses developed in 2 patients who received Tamoxifen therapy for more than 3 years.

In current study, gynaecological symptoms were found in $7(4.7 \%)$ patients of Tamoxifen group, $2(1.4 \%)$ patients of control group and $1(3.3 \%)$ of completed group. No correlation was found between gynecological symptoms and sonographic abnormalities, similar to studies by Ozseneretal ${ }^{29}$ andHann et $\mathrm{al}^{27}$. However, Teixeira et $\mathrm{al}^{16}$ and Deligdisch et $\mathrm{al}^{30}$ found a greater number of histological abnormalities and thickened 
endometrium in symptomatic patients compared to asymptomatic ones.

\section{Conclusion}

Tamoxifen therapy is associated with increased endometrial thickness and high uterine volume compared to patients without or completed therapy. The increase is also related to the duration of therapy. In this study, some gynecological pathologies were found in Tamoxifen-treated breast cancer patients. The endometrial thickness decreased gradually in breast cancer patients after completion of Tamoxifen therapy. Presence or absence of gynecological symptoms was found as an unreliable sign for diagnosing endometrial changes. Thus regular pelvic sonographic monitoring of patients on Tamoxifen therapy will be helpful to detect early changes.

\section{References}

1. Bray F, Ferlay J, Soerjomataram I, Siegel RL, Torre LA, Jemal A. Global cancer statistics 2018: GLOBOCAN estimates of incidence and mortality worldwide for 36 cancers in 185 countries. CA: a cancer journal for clinicians. 2018; 68(6):394424.

2. American College of Obstetricians and Gynecologists. Tamoxifen and uterinecancer.Committee opinion no. 601. Obstet Gynecol. 2014; 123:1394-7.

3. Yang G, Nowsheen S, Aziz K, Georgakilas AG. Toxicity and adverse effects of Tamoxifen and other anti-estrogen drugs. Pharmacology \& therapeutics. 2013;139(3):392-404.

4. Fisher B, Costantino JP, Wickerham DL, Cecchini RS, Cronin WM, Robidoux A, Bevers TB, Kavanah MT, Atkins JN, Margolese RG, Runowicz CD. Tamoxifen for the prevention of breast cancer: current status of the National Surgical Adjuvant Breast and Bowel Project P-1 study. Journal of the National Cancer Institute. 2005;97(22):1652-62

5. Machado F, Rodriguez JR, Leon JP, Parrilla JJ, Abad L. Tamoxifen and endometrial cancer. Is screening necessary? A review of the literature. European journal of gynaecological oncology. 2005;26(3):257-65.

6. Lee S, Kim YH, Kim SC, Joo JK, Seo DS, Kim KH, Lee KS. The effect of Tamoxifen therapy on the endometrium and ovarian cyst formation in patients with breast cancer. Obstetrics \& gynecology science. 2018; 61(5):615-20.

7. Mount SL, Eltabbakh GH. Tamoxifen and the female reproductive tract. Expert opinion on Pharmacotherapy. 2001;2(9):1399-413

8. Gupta S, Tandon VR, Kapoor B, Gupta A, Gupta GD, Khajuria V. Effects of tamoxifen therapy on the endometrium in postmenopausal patients of breast cancer. Indian journal of pharmacology. 2006;38(4):289.

9. Colacurci N, De LS, De PF, Mele D, Fortunato N, Cassese S. Tamoxifen effects on endometrium. Pan Minerva Medica 2000;42(1):45-7

10. Cohen I. Endometrial pathologies associated with postmenopausal tamoxifen treatment. Gynecologic oncology. 2004;94(2):256-66

11. Bertelli G, Venturini M, Del Mastro L, Garrone O, Cosso $\mathrm{M}$, Gustavino $\mathrm{C}$, et al. Tamoxifen and the endometrium: findings of pelvic ultrasound examination. Breast cancer research and treatment. 1998;47(1):41-6
12. Lahti E, Blanco G, Kauppila A, Apaja-Sarkkinen M, Taskinen PJ, Laatikainen T. Endometrial changes in postmenopausal breast cancer patients receiving tamoxifen. Obstetrics and Gynecology. 1993;81(5 (Pt 1)):660-4

13. Garrone O, Bertelli G, Principe E, Lewis PD, Occelli M, Miraglio E, et al. A prospective randomized study of transvaginal ultrasound effects of tamoxifen and exemestane in postmenopausal women with early breast cancer. Tumori Journal. 2014;100(6):620-4

14. Chalas E, Costantino JP, Wickerham DL, Wolmark N, Lewis GC, Bergman C, Runowicz CD. Benign gynecologic conditions among participants in the Breast Cancer Prevention Trial. American journal of obstetrics and gynecology. 2005;192(4):1230-7

15. Polin SA, Ascher SM. The effect of tamoxifen on the genital tract. Cancer Imaging. 2008;8(1):135

16. Teixeira AC, Urban LA, Schwarz RS, Pereira C, Millani TC, Passos AP. Value of sonographic endometrial findings in patients under tamoxifen therapy. Radiologia Brasileira. 2007;40(6):365-9

17. Bergman L, Beelen ML, Gallee MP, Hollema H, Benraadt $\mathrm{J}$, van Leeuwen FE. Risk and prognosis of endometrial cancer after Tamoxifen for breast cancer. The Lancet. 2000;356(9233):881-7

18. Fung MF, Reid A, Faught W, Le T, Chenier C, Verma S, Brydon E, Fung KF. Prospective longitudinal study of ultrasound screening for endometrial abnormalities in women with breast cancer receiving Tamoxifen. Gynecologic oncology. 2003;91(1):154-9

19. Ashraf M, Biswas J, Majumdar S, Nayak S, Alam N, Mukherjee KK, Gupta S. Tamoxifen use in Indian women-adverse effects revisited. Asian Pacific Journal of Cancer Prevention. 2009;10(4):609-12.

20. Vosse M, Renard F, Coibion M, Neven P, Nogaret JM, Hertens D. Endometrial disorders in 406 breast cancer patients on tamoxifen: the case for less intensive monitoring. European Journal of Obstetrics \& Gynecology and Reproductive Biology. 2002;101(1):58-63

21. Umar UM, Isyaku K, Adamu YM, Abubakar SA, Kabo NA, Nura I, et al. Sonographic measurement of uterine dimensions in healthy nulliparous adults in Northwestern Nigeria. Sahel Medical Journal. 2017;20(1):1

22. Kim HS, Jeon YT, Kim YB. The effect of adjuvant hormonal therapy on the endometrium and ovary of breast cancer patients. Journal of gynecologic oncology. 2008;19(4):256-60

23. Kalampokas T, Sofoudis C, Anastasopoulos C, Boutas I, Melloy S, Kondi-Pafiti A, et al. Effect of tamoxifen on postmenopausal endometrium. European Journal of Gynaecological Oncology. 2013;34(4):325-8.

24. Fishman M, Boda M, Sheiner E, Rotmensch J, Abramowicz J. Changes in the sonographic appearance of the uterus after discontinuation of Tamoxifen therapy. Journal of Ultrasound In Medicine. 2006;25(4):469-73.

25. Hummeida ME, Salah R, Hussien I, Adam GK, Ali AA. Ultrasonographic Appearance of the Uterine Endometrium in Sudanese Breast Cancer Women on Tamoxifen Therapy. J Women's Health Care. 2014;4(215):2167-0420.

26. Menada MV, Papadia A, Lorenzi P, Costantini S, Bertelli GF, Ragni N. Modification of ultrasonographically measured endometrial thickness after discontinuation of adjuvant therapy with Tamoxifen in postmenopausal breast cancer patients. European Journal of Gynaecological Oncology. 2004;25(3):321-3.

27. Hann LE, Giess CS, Bach AM, Tao Y, Baum HJ, Barakat RR. Endometrial thickness in tamoxifen-treated patients: correlation with clinical and pathologic findings. AJR. American Journal of Roentgenology 1997;168(3):657-61.

28. Le Donne M., Lentini M., DeMeo L., Benedetto V, Misiti, M. Uterine pathologies in patients undergoing tamoxifen 
therapy for breast cancer: ultrasonographic, hysteroscopic and histological findings. European Journal Of Gynaecological Oncology, 2006;27(1):4

29. Ozşener S, Ozaran A, Itil I, Dikmen Y. Endometrial pathology of 104 postmenopausal breast cancer patients treated with tamoxifen. European Journal of Gynaecological Oncology 1998;19(6):580-3.

30. Deligdisch L, Kalir T, Cohen CJ, de Latour M, Le Bouedec G, Penault-Llorca F. Endometrial histopathology in 700 patients treated with tamoxifen for breast cancer. Gynecologic Oncology 2000;78(2):181-6 